\title{
Editorial by the outgoing Editor-in-Chief
}

\section{B. Dattaguru ${ }^{1}$}

Received: 30 November 2019/Accepted: 30 November 2019/Published online: 7 December 2019

(C) Institute of Smart Structures \& Systems, Department of Aerospace Engineering, Indian Institute of Science, Bangalore 2019

Dear members of ISSS, readers and contributors to ISSS Journal,

I have been working as the Editor-in-Chief (EIC) of ISSS Journal on "Micro and Smart Systems" since 2017. I have completed 3 years and the current issue is my last effort. In my period as EIC, I had unstinting support from Prof. K. J. Vinoy who was also the President of ISSS during that period. He supported me in handling articles through the Editorial Manager and in the choice of reviewers and I profess my sincere thanks to him. All members of the Editorial Board provided excellent cooperation during the review process and I thank them all. Thanks are due to Prof. S. Gopalakrishnan who was the ISSS President for that part of the period, for being very helpful in many ways. I respectfully thank Dr. V. K. Aatre, the Founder President of ISSS, for providing me the opportunity to work as EIC of the Journal and also for his enormous help throughout my tenure. My thanks to all authors of papers whose timely contributions helped a lot to bring out the Journal issues during these past 3 years.
We initiated publishing this journal through Springer in 2017. Many thanks to all members of the Springer team for helping in promptly putting the papers on the web when the review was complete and for bringing out the printed issue systematically. The initial period was slack and we could only satisfy $70-80 \%$ of the papers requirement compared to what Springer was expecting. Our numbers are increasing now and I hope the new Editorial Board will take the Journal to new heights in both quality and quantity in terms of the number of papers. Steps are being taken to advertise the Journal. The new Editorial Board needs help from all of you to popularize the Journal.

The present Editorial Board will be stepping down in the new year 2020. I wish the best to the continuing and new members and the new EiC, Prof. S. Gopalakrishnan. We wish all the contributors and readers of the Journal and ISSS members a happy and prosperous new year 2020.

B. Dattaguru

\footnotetext{
$\triangle$ B. Dattaguru

datgurb@gmail.com

1 Bangalore, India
} 